Supporting Information for

\title{
Six-Membered Ring Chelate Complexes of Ru(II): \\ Structural and Photophysical Effects
}

Maria Abrahamsson ${ }^{1}$, Hans-Christian Becker ${ }^{1}$, and Leif Hammarström ${ }^{1 *}$

Celine Bonnefous ${ }^{2}$, Charles Chamchoumis ${ }^{2}$, and Randolph P. Thummel ${ }^{2 *}$

Figure S1: B3LYP/LANL2DZ isosurfaces at 0.02 for LUMO (upper panels) and HOMO (lower panels). The left panels are for $\left[\mathrm{Ru}(3)_{2}\right]^{2+}$ and the right panels are for $\left[\mathrm{Ru}(4)_{2}\right]^{2+}$.
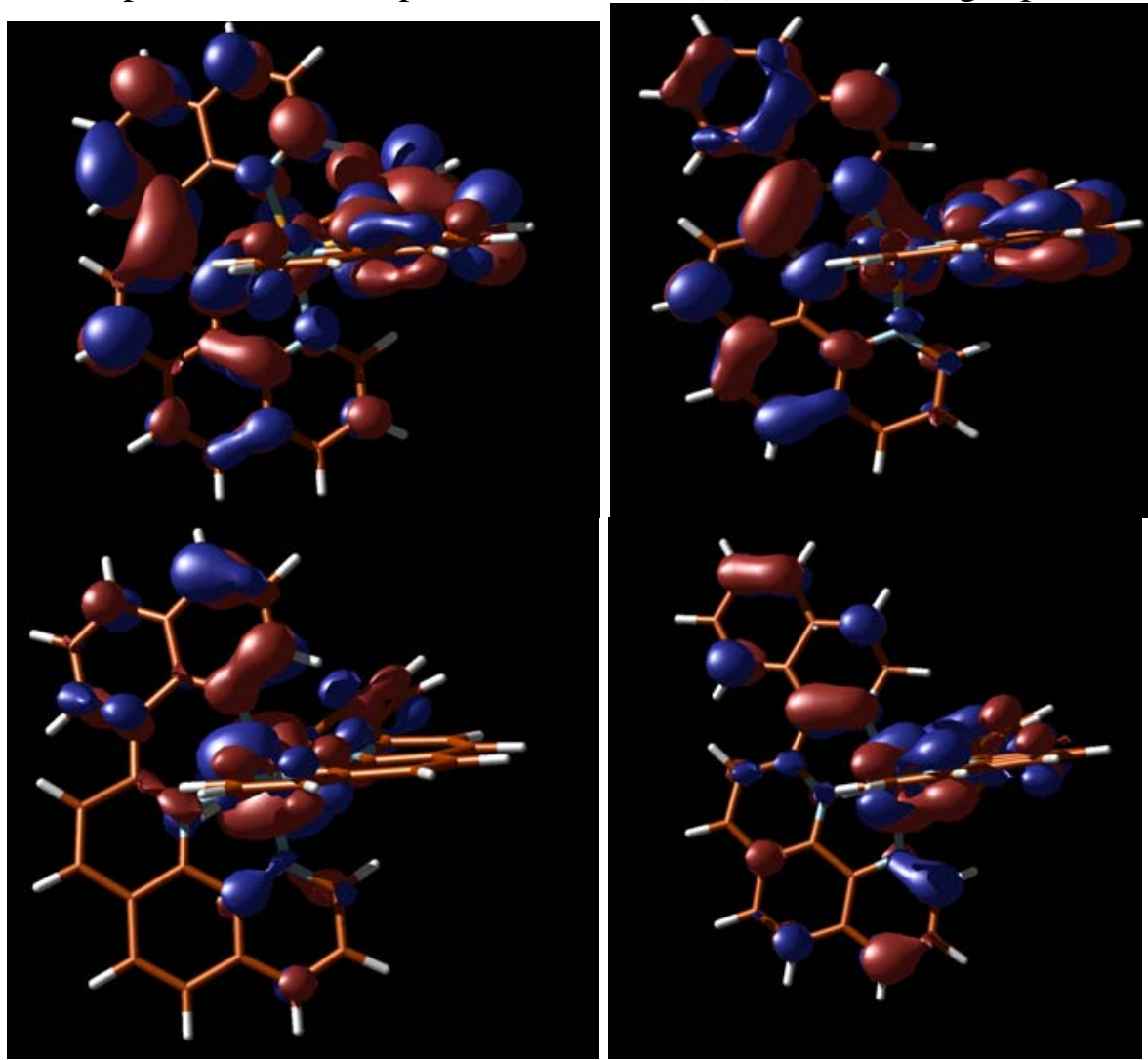